\title{
DELIVERING ENGINE DEMONSTRATORS FOR COMPETITIVE EVOLUTIONS OF THE EUROPEAN LAUNCHERS
}

\author{
J.-N. Caruana ${ }^{1}$, M. De Rosa ${ }^{2}$, T. Kachler ${ }^{2}$, W. Schoroth ${ }^{1}$, \\ and K. Underhill ${ }^{1}$ \\ ${ }^{1}$ ESA Launchers \\ 52 rue Jacques Hillairet, Paris 75012, France \\ ${ }^{2}$ ESA-ESTEC \\ 1 Keplerlaan, 2201 AZ Noordwijk, The Netherlands
}

\begin{abstract}
The year 2014 was one of achievements for the propulsion projects of the Future Launchers Preparatory Programme (FLPP). Highly relevant results were produced by hot-fire testing of three different engine demonstrators - a solid propulsion demonstrator focusing on pressure oscillations, a 5-kilonewton storable bipropellant engine, and a 25-kilonewton hybrid propulsion demonstrator. These concrete achievements were accompanied by the fast progress of a 115-kilonewton cryogenic expandercycle thrust chamber demonstrator which reached Preliminary Design Review (PDR) by end 2014, with hot-fire tests scheduled in 2017. These achievements give a solid grounding to the continuation and expansion of engine demonstrator projects at ESA Launchers.
\end{abstract}

\section{INTRODUCTION}

The FLPP of ESA Launchers has been since 2004 the technology investigation and maturation programme of the ESA Launchers Directorate. It manages several flagship integrated technology demonstrators as well as transversal generic technology maturation projects. The flagships are compact and flexible projects maturing technologies and system architectures from Technology Readiness Level (TRL) 3 to 6 , providing concrete results for the definition of the technical content and the specifications of subsequent development programmes.

The impact of preparatory demonstrators is particularly important in propulsion where the time and investment scales are large. Engine demonstrators are designed as prototypes assembling consistent sets of technologies. They are developed up to hot-fire testing, maturing the technologies in a system-driven

(C) The Authors, published by EDP Sciences. This is an open access article distributed under the terms of the Creative Commons Attribution License 4.0 (http://creativecommons.org/licenses/by/4.0/). 
project frame and in a representative engine environment. Thereby the technologies reach TRL6 fully integrated in engine systems, ready to be transferred to turnkey developments and flight qualification programmes. To a lesser extent, they can also support a running development programme by testing attractive alternative technologies embedded in the demonstrators.

Last year saw the hot-fire testing of three different engine demonstrators in excellent conditions, delivering very good results. A solid propulsion demonstrator focusing on pressure oscillations was fire tested in March 2014 near Bordeaux, France, followed by a 5-kilonewton storable bipropellant engine demonstrator tested between August and October 2014 in Lampoldshausen, Germany, and finally, a 25-kilonewton hybrid propulsion demonstrator was tested from October 2014 until December 2014 in Raufoss, Norway. In addition to these tests, a 115-kilonewton cryogenic expander-cycle thrust chamber demonstrator, started in 2013, made fast progress, reaching PDR at the end of 2014 and, thereby, keeping to the original planning for hot-fire tests in 2017. In the frame of this latter project, laser ignitions have been successfully performed at the P8 bench in Lampoldshausen, Germany. Generic and transverse technologies are also matured with this project, such as cryogenic valves for smart engine transients and combustion regime regulation, selective laser melting, and additive manufacturing.

These positive achievements are the result of, among other factors, an optimal tailoring of project management and quality assurance requirements, striking the right balance between the speed and affordability of project execution, on the one hand, and the safety of operations and quality of technical results, on the other. In the frame of these propulsion demonstrator projects, the different industrial contractors are empowered with the design authority, allowing them the freedom to respond optimally to the technology and functional requirements defined by ESA FLPP, chosen to maximize the benefit for future evolutions of the European launchers. The potential applications on launcher evolutions are considered at several levels, from the spin-off of an individual technology (e.g., laser ignition and sandwich nozzle) to the validation of a full protoengine as the foundation stone for a subsequent fast new engine development. In this respect, synergies between Ariane and Vega are considered and fostered.

This paper presents the different propulsion demonstrators developed in FLPP, their current status, and future perspectives starting with the hot-fire tests of 2014 and then describing in more detail the 115-kilonewton cryogenic expander-cycle thrust chamber demonstrator and its associated technology tests.

\section{$22014-$ A YEAR OF HOT FIRE TESTS}

This chapter presents in more detail the three demonstrators that underwent hot-fire testing last year, the logic behind their design, the test configuration, initial results, and the next steps. 


\subsection{POD-X — a Solid Propulsion Demonstrator Focusing on Pressure Oscillations}

As a major achievement, a pressure oscillation demonstrator (POD-X) developed in cooperation with CNES, the French Space Agency, culminated in a hot-firing test in spring 2014. The first POD-X firing (configuration demonstration model (DM) scale 2/9, Fig. 1) test took place successfully on March 11, 2014, at DGAEM EB4 test bench (St. Jean d'Illac, Bordeaux, France). Posttest inspections and Level 0 measurement analyses showed:

- a good fit to the Ariane 5 MPS (Moteurs à Propergol Solide) pressure law, with some slight deviations;

- pressure oscillation within the expected level and time ranges for 3 out of 4 expected bursts;

- frequency organization of the blasts/peaks similar to the MPS one;

- very high success rate of the transducers (about 95\%); and

- very good posttest status of the motor and test bench: confirmation that metallic structures can be reused many times.
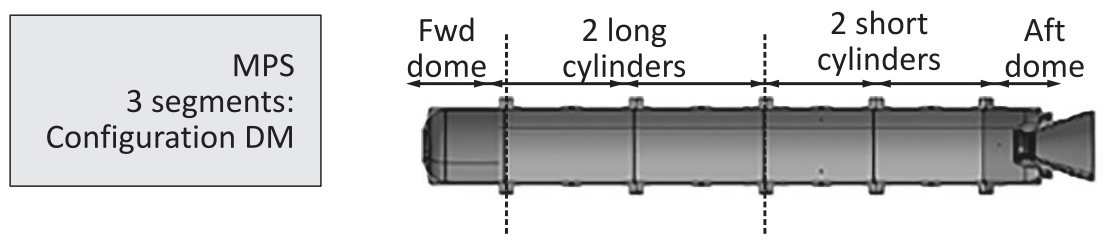

Figure 1 POD-X MPS configuration (Europropulsion)
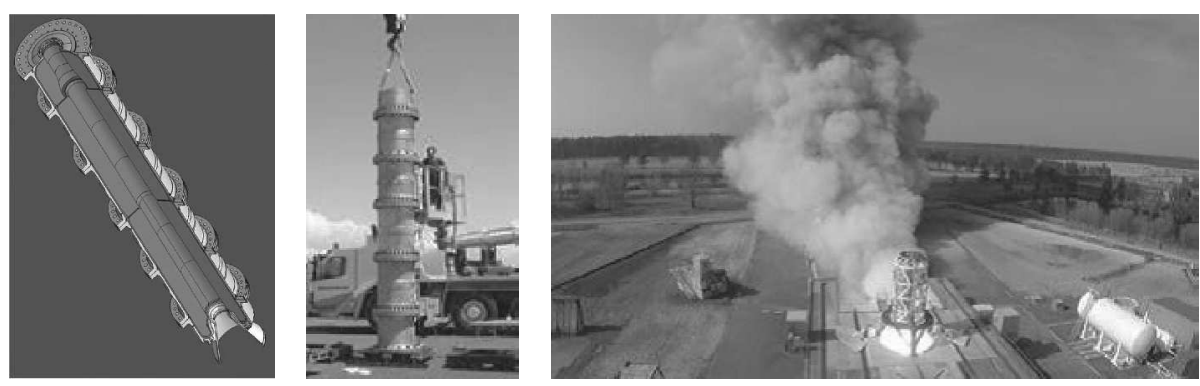

Figure 2 POD-X DM configuration and firing test (Europropulsion): length $\cong 5.9 \mathrm{~m}$; external diameter $\cong 750 \mathrm{~mm}$; total mass $\cong 7300 \mathrm{~kg}$; propellant mass $\cong 2700 \mathrm{~kg}$; burning time $\cong 29 \mathrm{~s} ;$ and about 300 measurement lines 
The test validated the POD-X experimental tool in terms of functional, mechanical, thermal, and ablative behavior as well as the interfaces with the test bench (Fig. 2). Presented in October 2014, the Level 1 analysis of the test data has enabled the clear definition of the domains requiring further analysis efforts and investments.

The POD-X Critical Design Review was held in May 2015 and concluded on the success of the DM firing test while delineating the future perspectives and options for the next POD-X test campaign. In front of future European launcher developments, reflections are on-going on the best programmatic options in order to decide on the next demonstrator configuration to be tested.

\subsection{Five-Kilonewton Storable Engine Demonstrator}

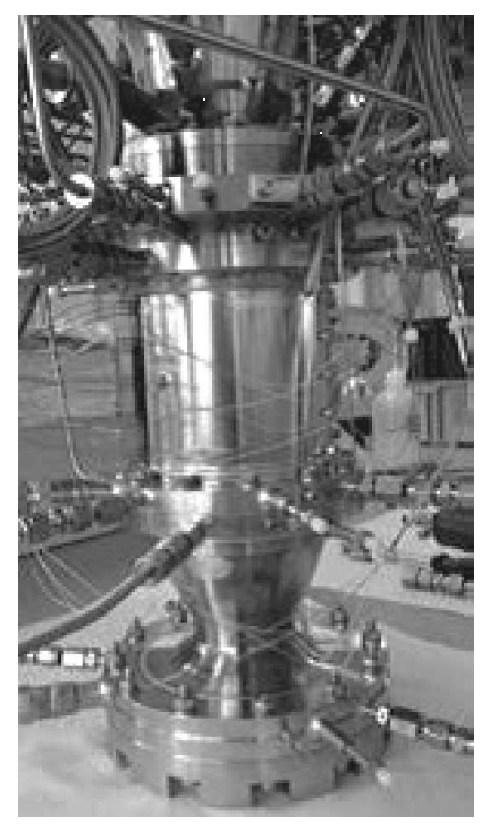

Figure 3 A 5-kilonewton storable engine demonstrator (Airbus Defence \& Space GmbH)
The goal of this project, started in mid-2010, is to demonstrate technologies for a pressure-fed engine in the thrust class of 3 to $8 \mathrm{kN}$ (Fig. 3), preparing versatile propulsion solutions for the European launchers. One leading potential application is the propulsion of the fourth stage of the Vega-C launcher. The same engine could also provide an alternative solution for launcher versatility as more diverse payload mission profiles appear on the launch market, especially with payloads using all-electric propulsion.

The technologies to be matured in this project were chosen through an analysis of market needs, system studies, and earlier test programmes. The main identified technologies are:

- nitrogen tetroxide (NTO) regenerative cooling (all monomethylhydrazine $(\mathrm{MMH})$ as regenerative cooling is not enough below a certain engine size);

- MMH film cooling; 
- improved injectors (higher efficiency and lower manufacturing cost);

- regenerative nozzle for storable engines (Aestus of Ariane 5 does not have a regenerative nozzle);

- innovative design of acoustic dampers;

- seamless uncooled nozzle skirt; and

- electrovalve demonstrators.

\subsubsection{Demonstrator architecture and technology tests}

After the completion of the concept studies and preliminary design, several technological component tests were carried out. Meanwhile, the engine long lead time items were released. The technological component tests covered two distinct areas: $(i)$ single injector characterization; and (ii) NTO cooling physical characterization.

Several injector designs have been manufactured, tested in water flow conditions and, eventually, in real propellant hot-firing conditions at the P2 bench in DLR Lampoldshausen, Germany. These tests supported the design justification of the injectors, especially with respect to stability and efficiency and drove the choice of injectors to be implemented on the engine demonstrator.

Regarding NTO cooling characterization, an electrically heated device was installed around a tube channelling the NTO. The cross section of the tube could be adapted to support the final design of the cooling channels on the engine. The electrically heated device was equipped with temperature sensors

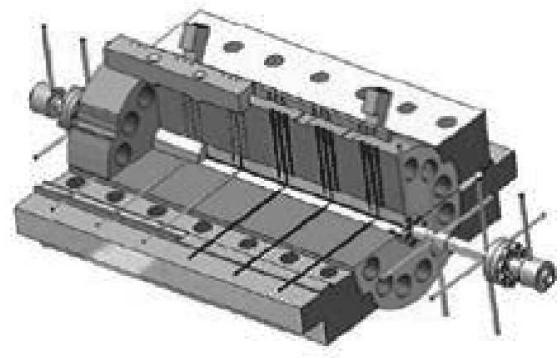

Figure 4 Electrically heated tube test design (Airbus Defence \& Space GmbH) so as to measure accurately the heat flux toward the tube and in the NTO (Fig. 4). The NTO flow rate could be modulated. This experiment provided precious results to justify the cooling channel design on the engine and ascertain the operational domain in hot-fire testing.

For the sake of cost efficiency, the project first went into hot-fire testing under sea-level conditions. Therefore, the first version of the engine demonstrator (5-kilonewton nominal thrust), tested in 2014, had a short expansion ratio in order to avoid flow separation (Fig. 5). With these constraints, it was decided to test the NTO regenerative cooling (one of the major new technologies) in the 


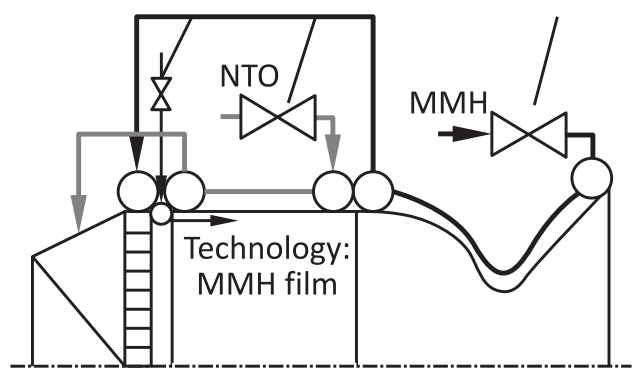

Figure 5 A 5-kilonewton storable engine demonstrator - NTO regenerative cooling in combustion chamber (Airbus Defence \& Space $\mathrm{GmbH})$ cylindrical part of the combustion chamber (Fig. 6).

Thanks to the modularity of the demonstrator concept, a configuration with NTO cooling in a regenerative nozzle part under altitude simulation conditions, with the rest of the engine cooled with fuel, is also possible. This latter configuration is closer to the design of a possible future flight engine.

The results from the first hot fire campaign show, however, that with the current design and certain restrictions, a pure MMH cooling might be possible in a thrust class larger than $5 \mathrm{kN}$. This would be beneficial to reduce the complexity, cost, and weight of a future application

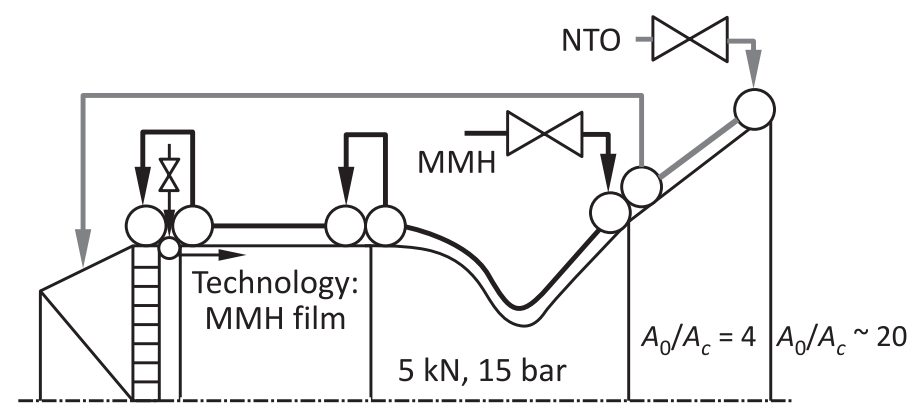

Figure 6 A 5-kilonewton storable engine demonstrator - NTO regenerative testing in nozzle (Airbus Defence \& Space GmbH)

\subsubsection{Hot fire tests -2014}

The manufacturing of the engine demonstrator and its spare parts was completed as planned in spring 2014. After successful acceptance checks, the engine was delivered at the test bench site, P2, in Lampoldshausen, Germany, and integrated into the test facility (Fig. 7).

The first successful hot-firing test of this engine took place on August 19, 2014 , and a total of 60 tests were performed, comprising 54 at sea level and 6 under vacuum at ignition (Fig. 8). The run times ranged from 1 to $110 \mathrm{~s}$, leading to 

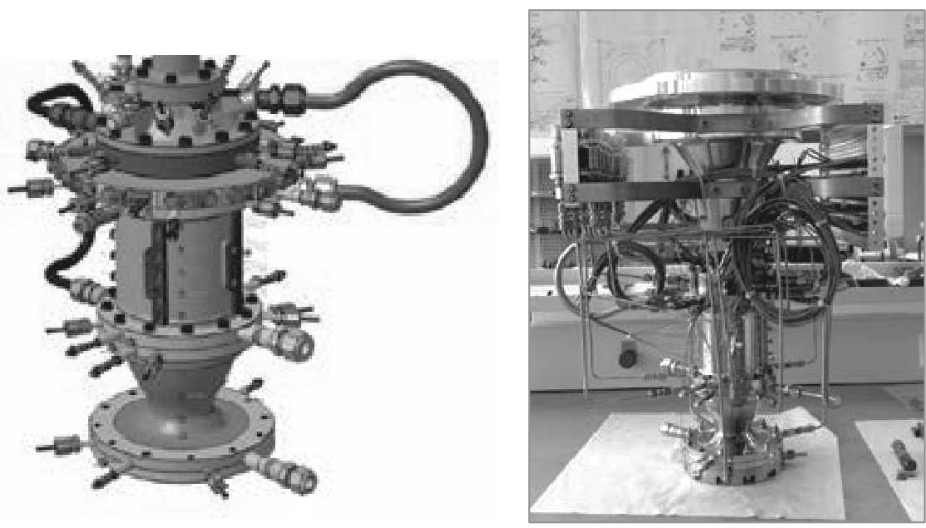

Figure 7 Engine demonstrator design and manufactured demonstrator (Airbus Defence \& Space $\mathrm{GmbH}$ )

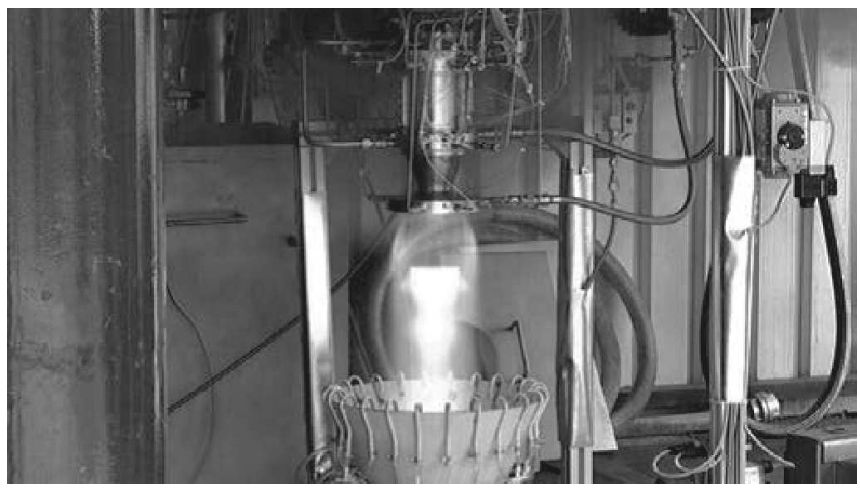

Figure 8 A 5-kilonewton storable engine demonstrator hot fire test (Airbus Defence \& Space $\mathrm{GmbH}$ )

a total run time during the campaign of $422.5 \mathrm{~s}$. The tests covered a wide range of parameters, for example, mixture ratio, combustion pressure, and propellant temperatures. Generally, the hardware performed well and as expected in the complete tested domain. The cooling performance of the regenerative cooling was designed so as to be sufficient in the whole demonstration domain. A film cooling device was designed as a dedicated technological objective for low-thrust engine applications and tested with two mass flows in several load points. Vacuum hot-firings with short duration into a static vacuum were performed with normal and low propellant temperatures. Those exhibited a similar behavior as the ground level tests, without any signs of instability. 
The test campaign lasted from August until October 2014 and provided valuable input for model refinement and future developments.

\subsubsection{Hot fire tests -2015}

The next planned test campaign (CAP-1) will use a capacitively cooled thrust chamber. The preparations for this campaign are progressing, with the first test planned for summer 2015. This test campaign will focus on the dynamic behavior of the thrust chamber (eigen-frequencies, damping, etc.), using bombs to excite high-frequency modes during the hot runs.

\section{Subprojects}

Several subprojects were started to mature peripheral technologies needed for an engine application. Those concern mainly valve and nozzle technologies:

- two valve demonstrator projects (by Techspace Aero in Belgium and Test Fuchs in Austria) were successfully performed up to a PDR status. One is based on a fully electric actuator, counting on a force-balanced poppet. The other relies on a more classical electropneumatic actuator; and

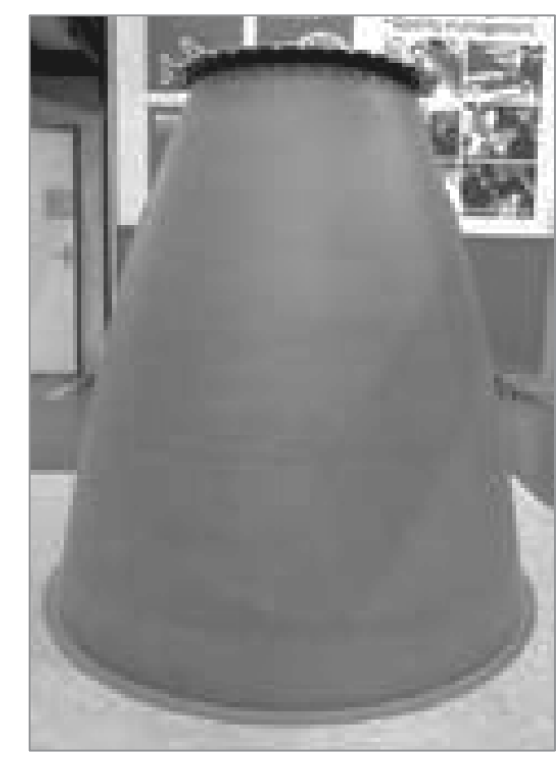

Figure 9 A 5-kilonewton storable engine demonstrator seamless nozzle skirt (Franke AG) 
- the nozzle (both cooled and uncooled) design and manufacturing will be prepared, for testing of the complete engine in altitude simulation. Already, a seamless uncooled nozzle skirt has been successfully manufactured by Franke in Switzerland out of a single metal sheet (Fig. 9). The process principle is the skewed rolling of a circular blank. The final wall thickness is around $0.5 \mathrm{~mm}$.

\subsubsection{Application to the Vega launcher}

After the positive results of the regenerative hot-firing test campaign in the third quarter of 2014, a detailed analysis of a derived flight engine powering the fourth stage of the Vega-C launcher has been running since the early days of 2015. This investigation, preparing for a new engine development and a first flight in 2018, is a concrete example of a possible transfer from a technology engine demonstrator to a launcher application. In such a context, the technical results obtained in FLPP are solid and precious references for swiftly defining the engine concept design and development logic.

\subsection{Hybrid Propulsion — Sounding Rocket Applications}

Regarding hybrid propulsion, the FLPP is developing a 25-kilonewton demonstrator engine, with the support of the Norwegian space agency (NSC), aimed at modular sounding rocket or microlauncher applications. A test campaign with an initial battleship design was performed on a Nammo test bench as from October 2014. After two monopropellant tests to tune the catalyst, the demonstrator of the Hybrid Unitary Motor performed 6 additional tests with both propellants (liquid and solid). The run time was progressively increased to $25 \mathrm{~s}$ during this campaign. The test results were in line with the predictions considering the thrust and chamber pressure. Based on the results from the first three firings (Configuration 1) where the fuel mass flow was lower than desirable at the end of the hot run, the design of the motor, especially the injector, was optimized (Fig. 10). Three additional tests with the adapted design (Configuration 2) showed an improved fuel regression rate in line with the predictions.

As the tests in 2014 have demonstrated the high potential of this technology, further optimization of the motor design, including a flight-like configuration (weight optimized and minimized residual fuel) is currently performed. This design will be extensively tested and refined in a test campaign starting at the end of 2015. In addition, an in-flight demonstration using a specifically developed oxidizer system on a sounding rocket is planned. In the long term, the results from this project will be used to develop a modular unitary motor, which can be clustered to achieve tailored characteristics for all stages of different sounding rockets and other applications. 


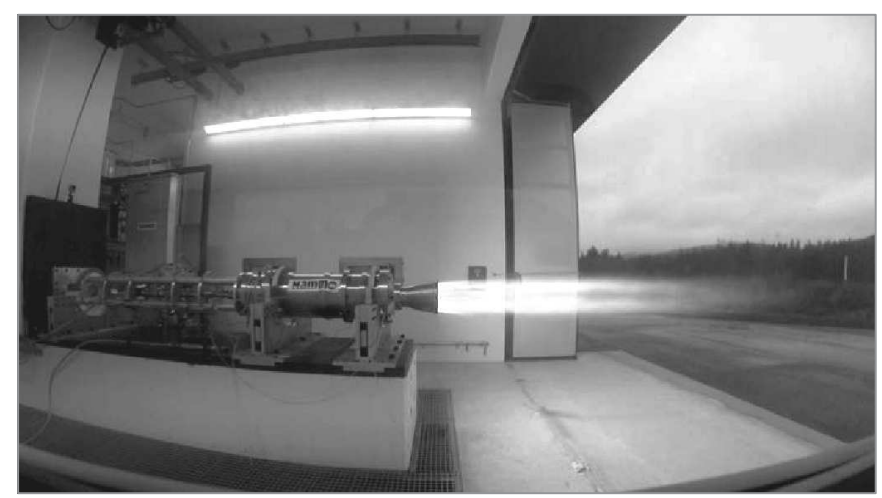

Figure 10 Hybrid engine demonstrator hot fire test, configuration 1, in Raufoss, Norway (Nammo)

\section{THE EXPANDER TECHNOLOGY INTEGRATED DEMONSTRATOR}

The Expander-cycle Technology Integrated Demonstrator (ETID), started mid2013, is a major constituent of the FLPP Period-3 programme. It prepares competitive evolutions of upper stage propulsion for Ariane 6 and Vega by assembling technologies that pave the way for the next generation of cryogenic upper stage engines in Europe.

The project was able to build on FLPP heritage in cryogenic engines, including: hot-fire testing demonstration of the Vinci engine in 2007-08 (FLPP 2.1); high-thrust engine PDR, subsystem tests (FLPP 2.1, 2.2); and cryogenic expander-cycle thrust chamber concept studies in 2012 (FLPP 2.2).

The key initial input to this project was a reflection on the competiveness factors of upper stage engines and how best to respond to them. This process resulted in the high level requirements, as outlined in Table 1.

Table 1 Upper stage propulsion competiveness factors translated into mission requirements

\begin{tabular}{ll}
\hline \multicolumn{1}{c}{ Competiveness factor } & \multicolumn{1}{c}{ Project response via mission requirements } \\
\hline High $I_{\mathrm{sp}}$ & Closed expander cycle, $\mathrm{LOx} / \mathrm{LH}_{2}$ \\
Low cost & Limited thrust, fixed nozzle, manufacturing choices \\
Low mass & Limited thrust, aluminum \\
High versatility & Large MR range, laser reignition \\
Easy integration and control & Electrification, fixed nozzle, radial igniters \\
\hline
\end{tabular}




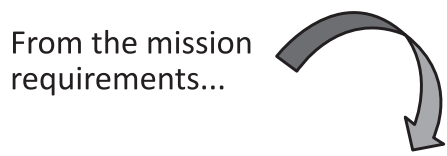

...to an optimal flight engine image $(\mathrm{FEI}) \ldots$
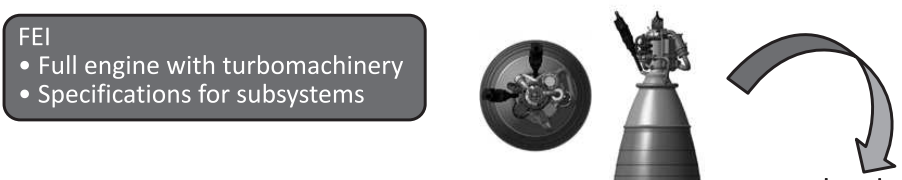

...to the demonstrator

(ETID)
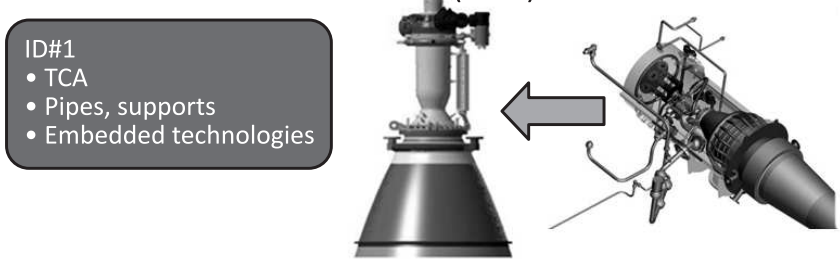

Figure 11 From requirements to flight engine to demonstrator

The mission requirements document (MRD) for this engine was centered on these competiveness factors through high-level specifications; however, few technologies were imposed - the technology push was to come from industry responding to the MRD. Through its inherent versatility, the demonstrator was to optimize potential applications and, therefore, synergies between applications - Ariane 6 upper stage propulsion incremental evolution, Vega-E third stage propulsion (LOx/Methane) but also considering several technologies benefiting the Vulcain 2 incremental evolution plan.

Considering a "test as you fly" principle, the representativeness to a potential flight engine was ensured by first defining the flight engine - Flight Engine Image (FEI), and then applying testing constraints to arrive at the engine demonstrator design - ETID (Fig. 11). The core of the project is dedicated to the design, manufacturing, and testing of the thrust chamber technology demonstrator - ID\#1. This first demonstrator is poised to be hot-fire tested in the first half of 2017. It should replicate in full scale an expander-cycle thrust chamber designed for an optimized flight engine.

\subsection{Design of Flight Engine Image}

As outlined above, the ETID is designed to be as close as possible to a future competitive evolution of the expander-cycle engine. To this end, an image engine 
is considered in this project as the virtual image of the target flight engine, optimized for the better performance and far lower cost of future evolutions of the European launchers. This image engine is used as a reference frame to identify more confidently the technologies to be matured and to define the most effective demonstrator. The demonstrator maximizes the technological content relevant to the fulfilment of the image engine missions. The first step in the project is, therefore, the design of the flight engine image, which is then adapted to a demonstrator compatible with the P3.2 test bench.

Supporting the mission requirements set out in Table 1, the following elements were also specified for the FEI:

- operation in both open and closed loop possible - enabling efficient domain explorations in hot-fire testing, an asset for the industrial acceptance of future flight engines;

- ambitious operating point accuracy requirements in open loop mode ( $\geq$ HM7B in-flight accuracy);

- inexistent, or negligible, water condensation on the inner wall of the thrust chamber assembly (TCA);

- strict cost and lead time requirements on an accepted FEI in series production - consideration of the industrialization, production, and exploitation activities from the start of the design cycle;

- inspectability and replacability of all critical items - nondestructive inspection (NDI) without disassembly, certain subsystems to be designed as line replaceable units (based on HM7B operations feedback); and

- technology requirements:

- new, low-cost, combustion chamber liner and jacket materials to be used;

- use of SLM on injector head, turbopumps;

- investigation of aluminum-alloy for the regenerative nozzle;

- minimization of helium consumption;

- lightweight material for pipes, no bellows; and

- improvement (mass, reliability, and accuracy) of the measurement chain.

The technical answer of the prime contractor, supported by their subcontractors, to these high-level requirements is detailed below, outlining the design of a competitive evolution of the expander-cycle engine. 


\subsubsection{Design methodology and modeling}

The project makes best use of the latest propulsion modeling capabilities. These computer models contribute to:

- establishing the steady-state model;

- defining the reference operating point;

- mapping the operating domain;

- identifying the functional specifications for the subsystems;

- checking the stability of the engine cycle;

- characterizing and optimizing the start-up and shutdown transients, defining the valve sequences;

- optimizing the mechanical design;

- characterizing the thermal behavior, and spotting the potential issues; and

- directly supporting the detailed design of the thrust chamber and the regenerative cooling channels.

New design technologies are also investigated and developed, such as RALP - Reliability Analysis and Life Prediction and Probabilistic Methods. Probabilistic methods allow sensitivity assessments of input parameters, identifying those that have the most impact on the life-spread, additionally quantitative margins of safety can be assessed, with the potential to allow mass reductions of up to $10 \%$ in certain components. This methodology has limited applicability due to the need for parameterization of all inputs and the need of statistically significant material sampling, such that only simpler forms can be considered. Proposed applications are pipes, bolted connections, thickness of coatings, etc. Potential applications have been found on the ID\#1 hardware on nonsafety critical items. Also, Thrust Chamber Life Prediction Based on Survival Analysis is investigated, the goal being to establish a statistical model for failure prediction of liquid rocket engine combustion devices based on empirical knowledge available from the development and test history of comparable components.

The hot-fire test results of ID\#1 will be compared to the numerical models, improving the validation status of the models and design methodologies used within the project, making them applicable for future development activities.

\subsubsection{Thrust chamber assembly}

The thrust chamber profile of the demonstrator is specified to be identical to the one of the optimized flight engine. 


\section{Combustion chamber}

The combustion chamber stays on the principle which has proven its mechanical robustness and cooling efficiency on HM7, Vulcain, and Vinci. This demonstrator project will contribute to enhancing this combustion chamber design, with the use of lighter and cheaper alloys, and optimized cooling channel design. The cooling channel design is optimized for the specified engine life, maximum heat pickup, minimum pressure drop, and avoidance of massive water condensation. As the performance of the expander cycle is mainly determined by the chamber heat pickup and the fuel turbopump efficiency, the possibility to increase the heat transfer in the combustion chamber will be tested. New low-cost materials are investigated for the liner and jacket as well as the optimization of production times.

\section{Nozzle}

The project is an opportunity to implement a regenerative nozzle part and continue the technological progress on the "sandwich" design. The regenerative nozzle part reduces the heat pickup assigned to the combustion chamber, therefore optimizing the global mass of the TCA. The most mastered stainless steel option is taken as reference for the realization of the nozzle item for the first demonstrator in 2017, while the maturation of manufacturing processes is continued for an eventual aluminum alloy regenerative nozzle. On the industrial standpoint, the FLPP contributes to the deployment of an automated manufacturing process and tools in industry, for the benefit of a future reliable and high performance production line of such nozzles. In addition, the avoidance of water condensation at the inner wall has led to evolved coolant circulation paths, designed and analyzed by numerical models.

\section{Injector head}

The injector head is identified as a good candidate to demonstrate the additive manufacturing. It is multifunctional, mechanically static, and of complex geometry. Dramatic cost reductions could result of this application. As the injector head is a massive part of the thrust chamber assembly, it is also the object of extended material trade-offs in order to reduce its mass. Innovative Advanced Porous Injector (API) designs on the face plate are also investigated.

\section{Igniter system}

The ignition system, traditionally installed at the center of the injection head, is proposed to be displaced on a ring mounted under the injector face plate. This layout would bring advantages in terms of accessibility and maintainability of the ignition system and would ease the implementation of multiple or redundant 
igniters for reliability and in-flight reignition capability. Innovative laser and spark ignition technologies are to be implemented on ID\#1. They are attractive as they are disconnected from the engine functional transients and would result in significant mass reductions; however, the constraints induced by their electronic systems must be carefully assessed.

\subsubsection{Other subsystems}

\section{Turbopumps}

Turbopumps and valves are considered in the FEI design according to a functional architecture similar to the one of the Vinci engine. In particular, valves bypassing the turbines will trim the thrust and the mixture ratio. The ETID is designed such that these components can be added in a modular way in later hot-fire tests, after ID\#1. Regarding the oxygen turbopump, robust dynamic seal package design and mass reduction are seen as the most interesting areas of progress. Moreover, the oxygen turbopump may be a one-to-one synergy between an $\mathrm{LOx} / \mathrm{LH}_{2}$ expander engine and a $\mathrm{LOx} /$ Methane engine. The hydrogen turbopump is a key component of the cryogenic expander engine, thanks to the limitation of the engine thrust, it is proposed to aim for a single stage pump impeller, thus contributing significantly to the general cost and mass reduction objectives of this important subsystem. For both turbopumps, objectives are also assigned in the directions of additive manufacturing, fluid bearing technology, and fast chilldown.

\section{Valves}

The cryogenic engine valves bring their own technological axes of progress to the project. The most prominent axis is about the systematic application of electric motor actuators. This choice enables a simplification of the engine functional layout and much wider possibilities of engine regulation, control, and autotests. Regarding the engine control, the electric motor actuators would be an efficient tool to explore and optimize the start-up and shutdown engine transients. They would also be involved in the engine closed loop mode. Last but not least, electric motor actuators may provide solutions to enhance the global engine failure tolerance in flight. The valves are also candidates for additive manufacturing.

\section{Pipes}

Regarding the mechanical architecture, a global and systematic process is applied to the choice of material, shapes, and dimensions for the pipes in order to reach a global mass optimum at engine level. This approach includes the search for the best positions of the subsystems. The pipes are specified to be without bellows. 


\section{Engine control system / health monitoring system}

The project opens the door to an analysis at engine system level of the advantages of an electronic controller. The controller could incorporate and execute the engine sequences, in particular the valve transients enabled by the electric actuators. The launcher onboard computer would only have to send the engine mode switch orders and receive the signals of proper execution sent back by the engine controller. The engine controller would also enable an automated check of the engine once it is integrated on the upper stage and on the launcher. This would provide very reproducible and low cost leak tests, valve actuation checks, igniter status, etc. all along the launcher production line up to liftoff. This would serve launcher integration complexity and liftoff availability, which are the major fields for competitiveness. The engine controller could also contribute to a better engine in-flight telemetry.

As part of the work on engine HMS, an improved sensor technology envisages the following goals: a static/dynamic pressure sensor, which records the dynamic pressure oscillations while preserving the correct static (dc) level of the signal; and minimizing the temperature sensitivity leading to a drift of the sensor.

\subsection{Technology Development Testing}

Although still in the design phase, the ETID project also contributed to the large number of experimental results obtained by FLPP propulsion projects in 2014. Successful subscale test campaigns, closed with Posttest Reviews in December 2014, for both laser and direct spark igniters have demonstrated the

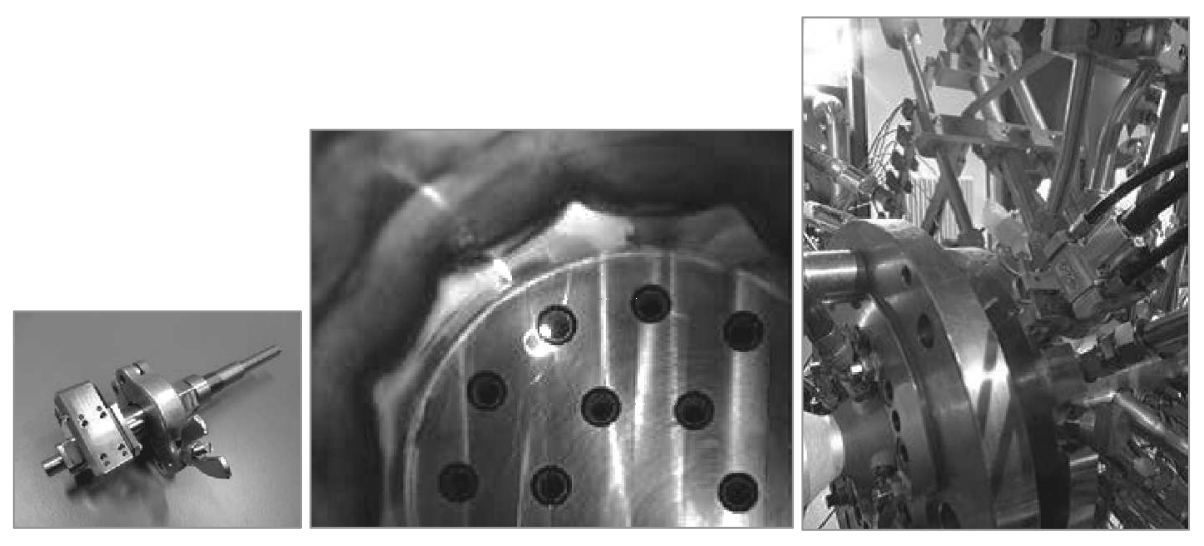

Figure 12 Laser igniter testing on the P8 test bench, Lampoldshausen (Airbus Safran Launchers $\mathrm{GmbH}$ ) 
potential of these technologies for multiple ignitions in relevant conditions. As an example, over 30 laser ignitions were demonstrated at the P8 test bench in Lampoldshausen, Germany (Fig. 12). The ignitions took place in a variety of propellant inlet conditions covering both initial and reignition environments. A subscale additive-layer manufactured injector head, coming from DLR national R\&D programme, was also successfully demonstrated during this test campaign, confirming the choice of this technology for ID\#1.

These new igniters technologies, with promising mass and performance reliably enabling multiple ignitions, have the potential to be applied to other combustion elements - such as the gas generator of Vulcain 2. Further testing on the P8 test bench in 2015 will help to confirm the interest of this application.

\subsection{ID\#1 - Hot Fire Tests in $\mathbf{2 0 1 7}$}

The ID\#1 demonstrator will be representative of the TCA of the flight engine, outlined in paragraph 3.1.2, with additional technology, such as light-weight pipes, as passengers during the hot-fire tests. The thrust chamber is composed of a combustion chamber body, a regenerative nozzle part, and an uncooled nozzle skirt. As a part of the adaption of the flight engine design to the demonstrator design, both nozzle parts have had to be shortened to fit the constraints of the P3.2 test bench. Different igniter technologies will be tested on the demonstrator, mounted radially on an igniter ring under the injection head. This TCA successfully passed PDR in September 2014 and is on course for a Mission Readiness Review in summer 2015.

Two sets of test hardware will be produced to have redundancy so that the test campaign is not delayed in case of hardware failure but also to enable testing different technologies. A nonexhaustive list of technologies included on ID\#1 is given below:

- enhanced heat pickup;

- cost-efficient combustion chamber liner and jacket;

- additive manufacturing for injector head;

- laser igniter, spark igniter, radial positioning for access, and redundancy;

- "sandwich" technology for regenerative nozzle (stainless steel for hot-fire tests, and development work on aluminum);

- optimized cooling channel design and cancellation of local overcooling;

- lightweight uncooled nozzle skirt; 


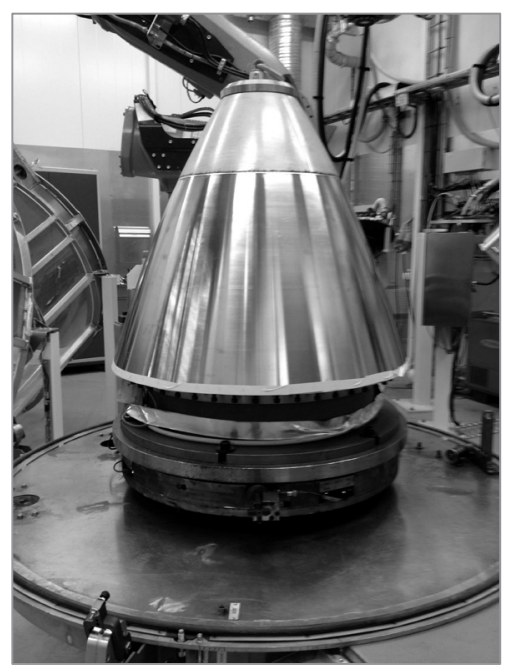

Figure 13 ID\#1 forerunner nozzle manufacture (GKN Aerospace)

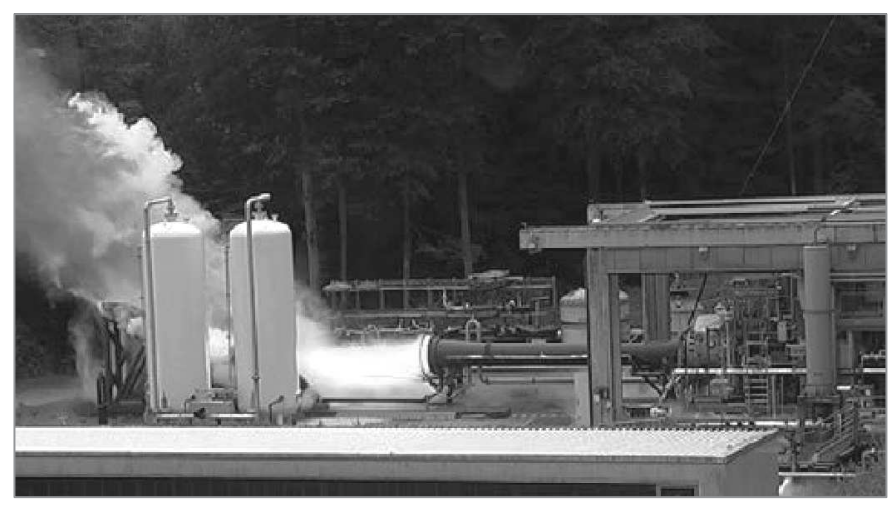

Figure 14 P3.2 test bench in Lampoldshausen, Germany (DLR Lampoldshausen)

- lightweight pipes; and

- new sensors/health monitoring.

To ensure timely delivery of test hardware in this fast-to-demonstration project, the manufacture of certain nozzle components is already undertaken on the forerunner (Fig. 13).

The ID\#1 hot-fire tests are planned for 2017 on the P3.2 test bench in DLR Lampoldshausen, Germany (Fig. 14). This test bench offers high pressure pro- 
pellant feeding capabilities enabling the firing of thrust chambers without turbopumps. At the P3.2, the project also wishes to make progress in the accurate measurement of thrust and high accuracy in other measurements such as propellant mass flow. The ID\#1 will be heavily instrumented, providing the maximum amount to experimental data with which to qualify technologies and analysis tools, the P3.2 must, therefore, design and implement a highly performant measurement system. The activities with DLR-Lampoldshausen on the preparation of the P3.2 test bench were officially started at the end of 2014, with the PDR of the P3.2 test bench modifications planned for summer 2015.

\subsection{Prospectives}

The ETID is an important brick of the propulsion technology roadmap, slated to provide mid- and long-term solutions serving the future competitiveness of Ariane 6, Vega, and beyond. Within the current phase of the project, the first demonstrator, ID\#1, will test innovative TCA technologies under representative conditions on the P3.2 test bench by 2017. In addition, the engine specifications for a flight image engine, based on the tested technologies, will be flowed down to a complete set of system and subsystem specifications, outlining the design of a potential flight engine.

Preparation for a possible continuation after the current step is underway, with the potential to maximize the technological returns of the demonstrator. The following are considered to be potential continuations for the project, depending on the occurrence of future opportunities:

- production and test of a partially or fully integrated ID\#02 engine demonstrator, with turbopumps and valves, updated based on the results of ID\#01 tests, paving the way for the development of a very competitive $\mathrm{LOx} / \mathrm{LH}_{2}$ expander-cycle engine evolution; and

- methanization of ID\#01, including hot-fire test campaign, and subsequent testing of a complete LOx/Methane engine demonstrator in the 100kilonewton thrust category.

Additionally, technology development work within this project already has the potential to contribute elements to the improvement of the existing cryogenic engines Vinci and Vulcain 2, for example, the laser ignition, where representative testing of this technology will be demonstrated within FLPP in 2015.

In conclusion, the ETID prepares effectively for low cost, high performance, and high reliability upper stage propulsion, in other words, a highly competitive evolution of the expander-cycle engine for the European launchers as from the mid-2020s. It provides also a real opportunity for synergies with a LOx/Methane engine as a possible very low cost upper stage application. 


\section{CONCLUDING REMARKS}

The achievements described in this paper set the pace for the continuation and expansion of such engine demonstrator projects at ESA Launchers. The propulsion activities in the ESA FLPP programme cover a large array of categories, from liquid propellants, both cryogenic and storable, to hybrid and solid. The FLPP is thereby preparing concretely and effectively the future competitiveness of the European launchers, with the support of the participating Member States and industrial partners. These propulsion projects are important for the European industrial contractors involved, as they provide to their key competence centers many large and cutting-edge tasks in technology maturation, system design, manufacturing, and testing.

Being at the upstream end of the development chain, the engine demonstrators are the best moment to introduce new structuring requirements with high potential impacts on future competitiveness such as dramatic cost and mass reductions. The technologies are evaluated on their ability to reduce costs, deliver versatile performance, and contribute to lean industrial processes for future evolutions of the European launchers. Integrated engine demonstrators are the most time- and cost-efficient way to assemble and mature the elected technologies up to real hot-firing conditions. Designed as prototypes, these demonstrators prepare well for their transfer into shorter and cost-effective flight engine developments.

The engine demonstrators anticipate also upcoming regulatory requirements such as the Clean Space policy, REACH (registration, evaluation, autorization, and restriction of chemicals), or material depletion guidelines. For instance, the FLPP is analyzing issues such as the switch from storable to nontoxic propellants or the guaranteed destruction of upper stages in passive reentries. For longer-term launcher evolutions and further steps toward competitiveness, the FLPP is closely involved in demonstration activities in the fields of very low cost $\mathrm{LOx} /$ hydrocarbon propulsion and reusability concepts. These activities are focused on lower stage applications.

The propulsion projects in FLPP are coordinated to provide a large, robust, and consistent range of solutions to the European launchers for the 2020s and beyond. They build on a long and successful background experience and help European launchers remain a world-class reference. 